\title{
Implementation of Power Factor Correction Using Solid State Switched Capacitors
}

\author{
Myint Myint Than ${ }^{1}$ \\ ${ }^{I}$ (Department of Electronic Engineering, Yangon Technological University, Republic of the Union of Myanmar)
}

\begin{abstract}
This paper deals with the implementation of automatic power factor correction system using solid state switched capacitors and Arduino UNO controller. The main objectives are to reduce the line loss, to reduce reactive power flows on the line and to avoid switching surge overvoltage due to switching on/off the capacitors. This paper describes the design and simulation of power factor correction using Arduino UNO controller. The power factor from the load is measured by using zero crossing circuit and phase shift detector, and then calculated the power factor according to the program and LCD will be used for display. This paper provides implementation done on Arduino UNO microcontroller using $C$ language software to program the microcontroller, Arduino program to determine time lag between current and voltage and Proteus 7.7 to simulate the power factor according to the load. This system senses the power factor and with the help of microcontroller switches, required number of capacitors in the capacitor bank. In this system, the reactive power will be generated by the bank of static capacitors. Design and simulation will be done by using the LM 358, MOC 3052, BTA 41, ICs, Arduino UNO Microcontroller and LCD display in this system.
\end{abstract}

Keywords: Power Factor, LM358, CD4070 BC, LCD, C language, Proteus7.7, Arduino UNO microcontroller.

\section{Introduction}

In electrical plants, the loads draw from the network electric power (active) as power supply source (e.g. personal computers, printers, diagnostic equipment, etc.) or convert it into other form of energy (e.g. electrical lamps or stoves) or into mechanical output (e.g. electrical motors). To get this, it is often necessary that the load exchanges with the network (with net null consumption) and the reactive energy is produced mainly from inductive type. This energy, even if not immediately converted into other forms, contributes to increase the total power flowing through in the electrical network, from the generators, all along the conductors, to the users. To smooth such negative effect, the power factor correction of the electrical plants is carried out. The power factor correction obtained by using capacitor banks to generate locally the reactive energy necessary for the transfer of electrical useful power, allows a better and more rational technical-economical management of the plants.

There are so many industries around the world and so are in Myanmar. Most of the industrial plants are using the inductive loads in infrastructure such as transformers and motors. Among them, the large industrial motors are essentially used in the industrial plants. Induction motors receive the grate reactive power from network for their proper function. Reactive power consumption causes the reduction of voltage of feeder in the plants and on the other hand, it causes the reduction of power factor of the whole plants. Therefore to improve the power factor is very important for all of the plants and even in the domestic industries and home appliances. According to that point, one of the best methods for the power factor improvement is the power factor correction (PFC) technique. The block diagram of power factor correction system is shown in Fig. 1.

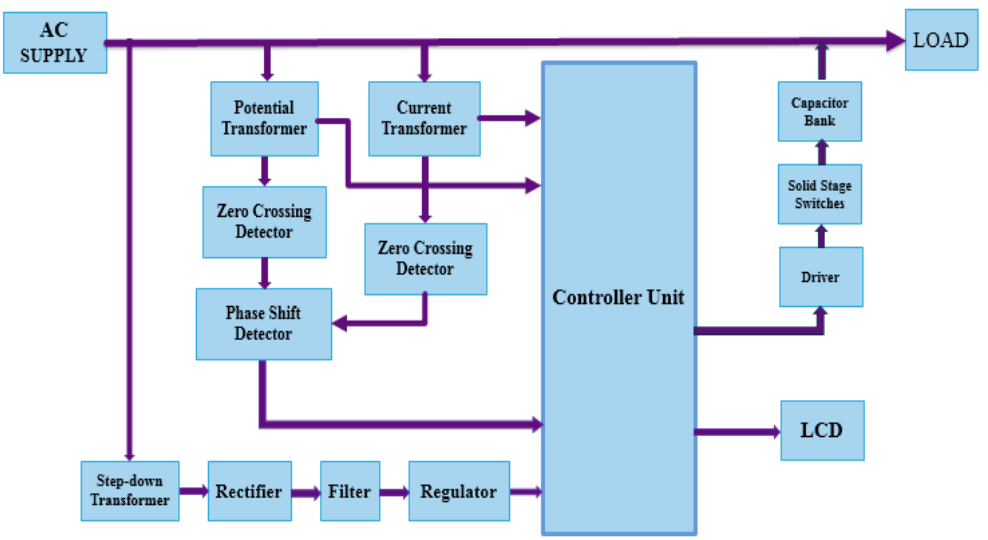

Figure. 1 Block Diagram of Power Factor Measuring System 


\section{Technology}

This system presents power factor correction (PFC) technique using solid state switched capacitors. This system describes the design and simulation of power factor correction using Arduino UNO controller. Measuring the power factor from the load by using LM358 zero crossing circuit and CD4070BC phase shift detector, and then calculating the power factor have been done according to the program and LCD will be used for display. If the power is not in the range, the switches are on/off conditioned by the controller unit and capacitors are activate/deacivate and improve the power factor. This system provides implementation done on Arduino UNO microcontroller using $\mathrm{C}$ language software to program the microcontroller, Arduino program to determine time lag between current and voltage and Proteus 7.7 to simulate the power factor according to the load.

The apparent power also referred to as total power delivered by utility company has two components.

(1) Productive Power that powers the equipment and performs the useful work. It is measured in $\mathrm{kW}$ (kilowatts).

(2) Reactive Power that generates magnetic fields to produce flux necessary for the operation of induction devices (AC motors, transformer, inductive furnaces, ovens etc.). It is measured in kVAR (kilovoltAmpere-Reactance).

Reactive Power produces no productive work. An inductive motor with power applied and no load on its shaft should draw almost nil productive power, since no output work is being accomplished until a load is applied. The current associated with no-load motor readings is almost entirely "Reactive" Power. As a load is applied to the shaft of the motor, the "Reactive" Power requirement will change only a small amount. The Productive Power is the power that is transferred from electrical energy to some other form of energy (i.e. such as heat energy or mechanical energy). The apparent power is always in excess of the productive power for inductive loads and is dependent on the type of machine in use. The working power $(\mathrm{kW})$ and reactive power (kVAR) together make up apparent power, which is measured in kilovolt amperes (kVA). Graphically it can be represented as:

$$
\text { Power factor }=\frac{\mathrm{kW} \text { (Productive Power) }}{\mathrm{kVA}(\text { Total Power) }}
$$

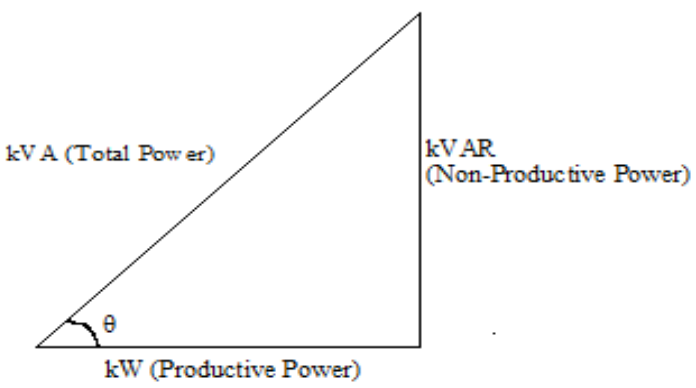

The cosine of the phase angle $\theta$ between the $\mathrm{kVA}$ and the $\mathrm{kW}$ components represents the power factor of the load. kVAR represents the non-productive reactive power and $\theta$ is lagging phase angle [1].

The Relationship between $\mathrm{kVA}, \mathrm{kW}$ and $\mathrm{kVAR}$ is non-linear and is expressed:

$$
\mathrm{kVA}^{2}=\mathrm{kW} 2+\mathrm{kVAR}^{2}
$$

Benefits of Power Factor Correction are:

(1) Reduce Utility Power Bills,

(2) Increase System Capacity,

(3) Improve System Operating Characteristics (Gain Voltage), and

(4) Improve System Operating Characteristics (Reduce Line Losses).

\section{A. Zero Crossing Detector}

Zero crossing detector is used to detect sine wave zero crossing from positive half cycle to negative half cycle or negative half cycle. To measure time difference between two waves is to detect zero crossing of two waves. The $230 \mathrm{~V}, 50 \mathrm{~Hz}$ is step downed using voltage transformer and current transformer is used to extract the waveforms of current. The output of the voltage transformer is proportional to the voltage across the load and output of current transformer is proportional to the current through the load. These waveforms are fed 
to voltage comparators constructed using operational amplifier. It is a zero crossing detector, and its output changes during zero crossing of the current and voltage waveforms. These outputs are fed to the controller unit which does the further power factor calculations. Zero crossing detector using LM 358 as a comparator is shown in Fig.2.

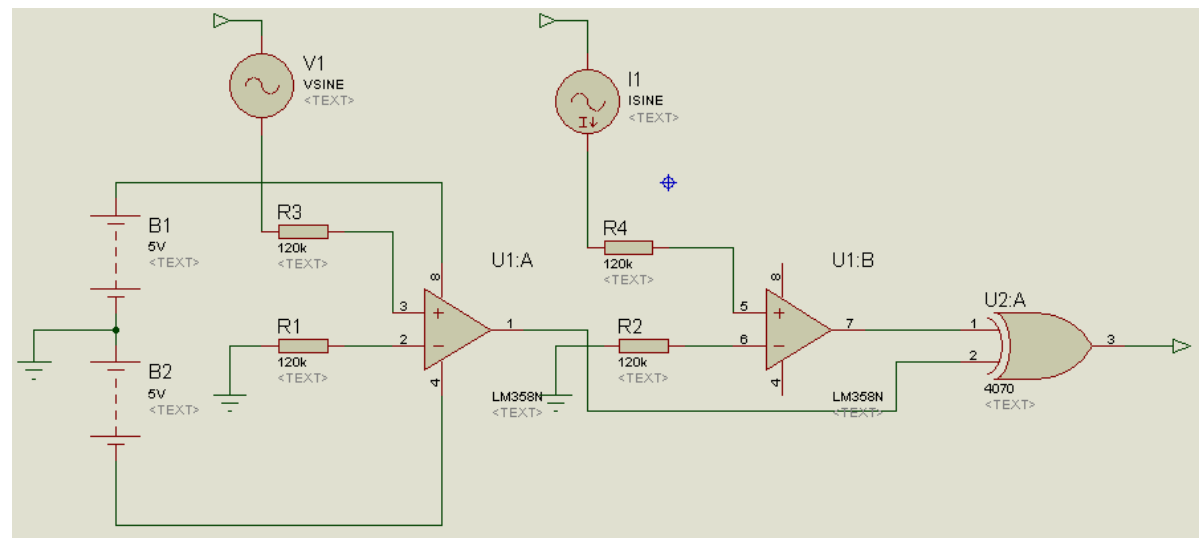

Figure. 2 Zero crossing detector using LM358 as a comparator

\section{Solid State Switch}

Solid state switches are electronic switching devices that can operate on or off positions when a small external voltages is applied from the microcontroller. In AC circuits, solid state relays (SCR or TRIAC) switch on at the points of zero load current. The circuit will never be interrupted in the middle of a sine wave peak, preventing the large transient voltages that would otherwise occur due to sudden collapse of the magnetic field around the inductance. This feature is called zero-crossover switching. Many advantages appear by using the solid state switches in this system. There are slimmer profile, allowing tighter packing, totally silent operation and switch faster than electromechanical relays; the switching time of a typical optically coupled SSR is dependent on the time needed to power the LED on and off of the order of microseconds to milliseconds. It can increase lifetime, even if it is activated many times, as there are no moving parts to wear and no contacts to pit or build up carbon. Output resistance remains constant regardless amount of use. Clean, bounce less operation, no sparking, allows it to be used in explosive environments, where it is critical that no spark is generated during switching. It is inherently smaller than a mechanical relay of similar specification. It is much less sensitive to storage and operating environment factors such as mechanical shock, vibration, humidity, and external magnetic fields.

\section{Capacitor Bank}

There are two categories of connecting capacitor bank. They are shunt and series connecting. Among these two categories, shunt capacitors are more commonly used in the power system of all voltage levels. There are some specific advantages of using shunt capacitors such as:

(1) It reduces line current of the system.

(2) It improves voltage level of the load.

(3) It also reduces system losses.

(4) It improves power factor of the source current.

(5) It reduces load of the alternator.

(6) It reduces capital investment per megawatt of the load.

All the above-mentioned benefits come from the fact that the effect of capacitor reduces reactive current flowing through the whole system. Shunt capacitor draws almost fixed amount of leading current which is superimposed on the load current and consequently reduces reactive components of the load and hence improves the power factor of the system. Series capacitor on the other hand has no control over flow of current. As these are connected in series with load, the load current always passed through series capacitor bank. The capacitive reactance of series capacitor neutralizes the inductive reactance of the line hence, reduces, effective reactance of the line.

\section{E. Controller Unit}

Controller unit which represented Arduino UNO is the heart of this Automatic Power Factor Controller, it finds, displays and controls the Power Factor. To correct power factor, first finding the current power factor is needed. It displays the calculated power factor in the LCD display and switches ON the 
capacitors. The controller calculates the time difference between the zero crossing points of current and voltage, which is directly proportional to the power factor. Moreover it determines the power factor according to the program and to get the desired values by using the compensation of the capacitors. Depending on the power factor range the switches are activating the on stage with the control of the program. The required numbers of capacitors are connected in parallel to the load as required.

\section{F. Circuit Diagram of the System}

Complete circuit diagram of this system is shown in Fig. 3.

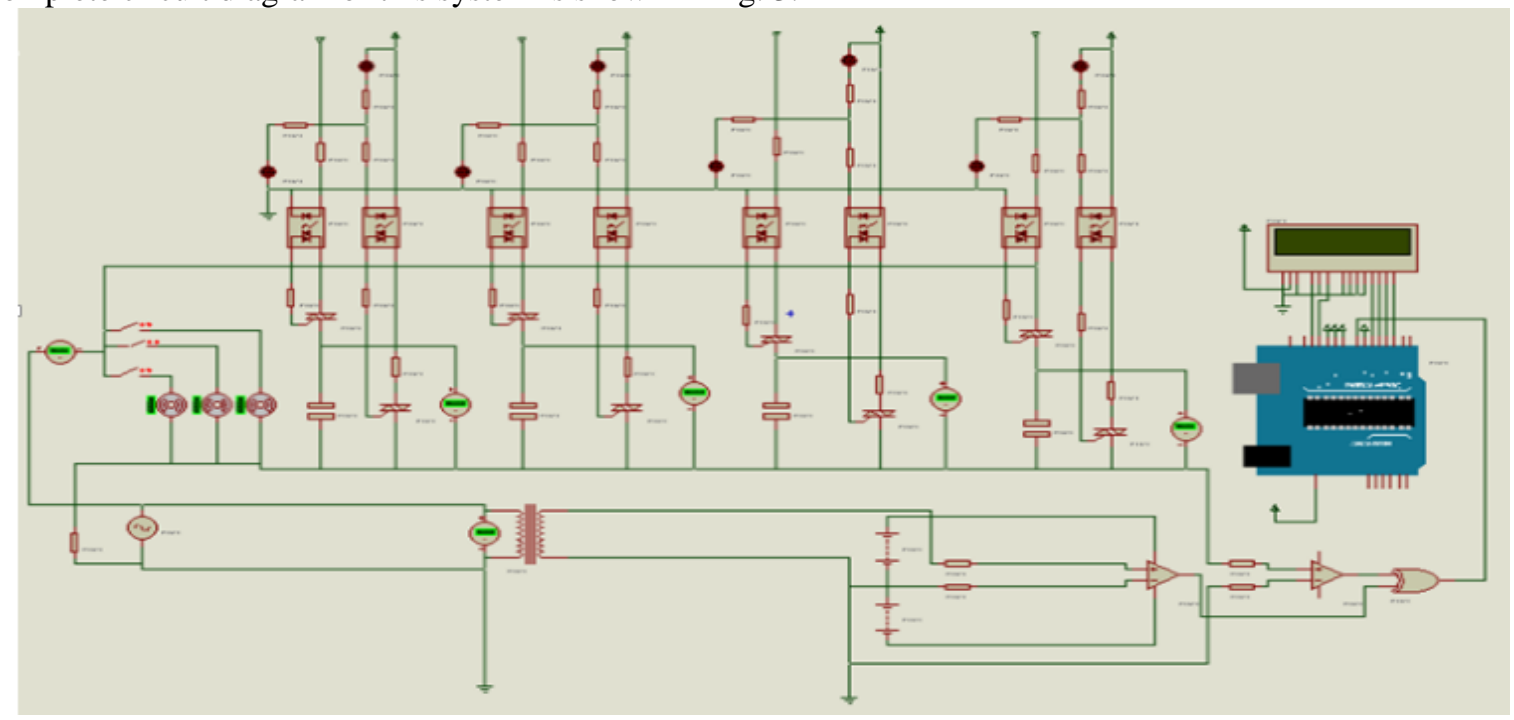

Figure. 3 Circuit Diagram of the System

\section{Design Calculation}

A. Calculation of Power Factor Using Theory

In this system, the selected loads are as follows:

Selected values for motor 1

$\mathrm{R}=50 \Omega, \mathrm{L}=200 \mathrm{mH}, \mathrm{f}=50 \mathrm{~Hz}$

Selected values for motor 2

$\mathrm{R}=50 \Omega, \mathrm{L}=250 \mathrm{mH}, \mathrm{f}=50 \mathrm{~Hz}$

Selected values for motor 3

$\mathrm{R}=50 \Omega, \mathrm{L}=200 \mathrm{mH}, \mathrm{f}=50 \mathrm{~Hz}$

Motor $1 \mathrm{ON}$, supply voltage, $\mathrm{V}=230 \angle 0{ }^{\circ} \mathrm{V}$

$\mathrm{Z}_{1}=\mathrm{R}+\mathrm{j} \omega \mathrm{l}=\mathrm{R}+\mathrm{j} 2 \pi \mathrm{fl}$

$\mathrm{Z}_{1}=(50+\mathrm{j} 20 \pi) \Omega=80.29845 \angle 51.488^{\circ} \Omega$

$\mathrm{I}=\mathrm{V} / \mathrm{Z}_{1}=2.864 \angle-51.488^{\circ} \mathrm{A}$

$\mathrm{P} . \mathrm{F}=\cos (51.488)=0.6227$ (Lagging)

Motor 1 , Motor 2 and Motor $3 \mathrm{ON}$, supply voltage, $\mathrm{V}=230 \angle 0{ }^{\circ} \mathrm{V}$

$$
\begin{aligned}
& Z_{12 a}=Z_{1} / / Z_{2} / / Z_{a}=(50+j 20 \pi) / /(50+j 25 \pi) / /(50+j 20 \pi]=28.085 \angle 53.3041^{\circ} \Omega \\
& I=\frac{V}{Z_{123}}=8.189 \angle-53.3041^{\prime} \mathrm{A} \\
& P_{.} F=\cos (53.3041)=0.5976 \text { (Lagging) }
\end{aligned}
$$

\section{B. Calculation of Compensated Capacitor Units}

This calculation describes the compensated capacitors for different conditions.

Motor $1 \mathrm{ON}$

$\mathrm{V}=230 \mathrm{~V}, \mathrm{I}=2.864 \angle 51.68 \mathrm{~A}$

Initial power factor $=\cos \theta_{1}=0.62$

$\theta_{1}=51.46^{\circ}$

Target power factor $=\cos \theta_{2}=0.94$

$\theta_{2}=19.95^{\circ}$

$P_{1}=V I \cos \theta_{1}=230 \times 2.864 \times 0.62$

$=408.41 \mathrm{~W}$ 
$Q_{c}=Q_{1}-Q_{2}$

$=\mathrm{P}\left(\tan \theta_{1}-\tan \theta_{2}\right)=408.41(\tan 51.46-\tan 19.95)$

$=367.569 \mathrm{Var}$

For capacitor,

$C_{1}=\frac{\mathrm{kVar}}{2 \pi f V^{2} \times 10^{-8}}=\frac{367.569 \times 10^{-8}}{2 \pi \times 50 \times 230^{2} \times 10^{-8}}=22.117 \mu \mathrm{F}$

Motor 1,2 and 3 ON

$\mathrm{V}=230 \mathrm{~V}, \mathrm{I}=8.1989$

Initial power factor $=\cos \theta_{1}=0.60$

$\theta_{1}=53.13^{\circ}$

Target power factor $=\cos \theta_{2}=0.94$

$\theta_{2}=19.95^{\circ}$

$\mathrm{P}=\mathrm{VI} \cos \theta_{1}=230 \times 8.1989 \times 0.6$

$=1131.4482 \mathrm{~W}$

$Q_{c}=Q_{1}-Q_{2}$

$=\mathrm{P}\left(\tan \theta_{1}-\tan \theta_{2}\right)=1131.4482(\tan 53.13-\tan 19.95)=1097.896 \mathrm{Var}$

For capacitor, $\mathrm{C}=\frac{\mathrm{kVar}}{2 \mathrm{mfV}^{2} \times 10^{-\mathrm{g}}}$

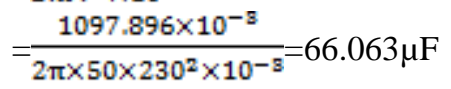

Table 1. Capacitance Values of Different Loads

\begin{tabular}{|c|c|c|c|c|c|c|}
\hline Motor & $\begin{array}{l}\text { Initial } \\
\text { power } \\
\text { factor }\end{array}$ & $\begin{array}{l}\text { Target } \\
\text { power } \\
\text { factor }\end{array}$ & $\begin{array}{l}\mathrm{K}=\left(\tan \theta_{1}-\tan \theta_{2}\right) \\
(\mathrm{kvar} / \mathrm{kW})\end{array}$ & $\begin{array}{l}\mathrm{P}= \\
\text { VIcos } \theta_{1} \\
(\mathrm{~W})\end{array}$ & $\begin{array}{l}Q_{c}=\mathrm{K} \times \mathrm{P} \\
(\text { Var })\end{array}$ & $\mathrm{C}=\frac{\mathrm{kV} \text { Var }}{2 \pi \mathrm{fV}{ }^{2} \times 10^{-5}} \mu \mathrm{F}$ \\
\hline Motor 1 & 0.62 & 0.94 & 0.90 & 408.41 & 367.569 & 22.117 \\
\hline Motor 2 & 0.54 & 0.94 & 1.20 & 306.774 & 368.129 & 22.151 \\
\hline Motor 3 & 0.62 & 0.94 & 0.90 & 408.41 & 367.569 & 22.117 \\
\hline Motor 1,2 & 0.58 & 0.94 & 1.04 & 710.622 & 739.047 & 44.469 \\
\hline Motor 1,3 & 0.62 & 0.94 & 0.9 & 816.96 & 735.259 & 44.24 \\
\hline Motor 2,3 & 0.58 & 0.94 & 1.04 & 710.622 & 739.047 & 44.469 \\
\hline Motor1,2,3 & 0.60 & 0.94 & 0.97 & 1131.448 & 1097.50 & 66.039 \\
\hline
\end{tabular}

Table 2 Selected Capacitor Values

\begin{tabular}{|c|c|c|c|c|}
\hline SW 4 (47 $\boldsymbol{\mu F})$ & $\mathbf{S W 3}(\mathbf{2 2} \boldsymbol{\mu F})$ & $\mathbf{S W 2} \mathbf{( 4 . 7} \boldsymbol{\mu F})$ & $\mathbf{S W 1}(\mathbf{2 . 2} \boldsymbol{\mu} \mathbf{F})$ & Total capacitor $(\boldsymbol{\mu F})$ \\
\hline 0 & 0 & 0 & 0 & 0 \\
\hline 0 & 0 & 0 & 1 & 2.2 \\
\hline 0 & 0 & 1 & 0 & 4.7 \\
\hline 0 & 0 & 1 & 1 & 22 \\
\hline 0 & 1 & 0 & 0 & 24.2 \\
\hline 0 & 1 & 0 & 0 & 26.7 \\
\hline 0 & 1 & 1 & 1 & 28.9 \\
\hline 0 & 1 & 1 & 0 & 47 \\
\hline 1 & 0 & 0 & 1 & 49.2 \\
\hline 1 & 0 & 0 & 0 & 51.7 \\
\hline 1 & 0 & 1 & 1 & 53.9 \\
\hline 1 & 0 & 1 & 0 & 69 \\
\hline 1 & 1 & 0 & 1 & 71.2 \\
\hline 1 & 1 & 0 & 0 & 73.7 \\
\hline
\end{tabular}

\section{Calculation of Capacitor Discharge Circuit}

This section describes the calculation of capacitor discharge circuit:

Supply Voltage, $V_{\max }=\sqrt{2} \times 230=325 \mathrm{~V}$.

$$
V_{C(\max )}=325 \mathrm{~V}
$$

Select Discharge Time $\mathrm{t}=2 \mathrm{sec}$

$$
\begin{aligned}
& V_{C_{(\min )}}=10 \% \text { of } V_{C_{(\max )}}=10 \% \text { of } 325 \mathrm{~V}=32.5 \mathrm{~V} \\
& V_{\mathrm{C}_{(\mathrm{t})}}=\mathrm{V}_{0} \mathrm{e}^{-t_{\mathrm{t}} / \mathrm{t}}=\mathrm{V}_{0} \mathrm{e}^{-\mathrm{t} / \mathrm{RC}}
\end{aligned}
$$


$\mathrm{V}_{\mathrm{c}(\mathrm{min})}=\mathrm{V}_{0} \mathrm{e}^{-2 / \mathrm{R} \times \mathrm{C}}$

$32.5=325 \mathrm{e}^{-{ }^{2} / \mathrm{R} \times \mathrm{C}}$

$\mathrm{e}^{-{ }^{2} / \mathrm{R} \times \mathrm{C}}=0.1$

$\frac{-2}{\mathrm{RC}}=\ln 0.1$

$\mathrm{R}=\frac{-2}{\operatorname{In} 0.1 \times \mathrm{C}}=\frac{2}{2 . \mathrm{a} \times \mathrm{C}}$

For $\mathrm{C}_{1}=2.2 \mu \mathrm{F}_{x}$

Discharge Resistor, $\mathrm{R}_{1}=\frac{2}{2.3 \times 2.2 \times 10^{-6}}=395.26 \mathrm{k} \Omega$

Select $\mathrm{R}_{1}=390 \mathrm{k} \Omega$

For $\mathrm{C}_{2}=4.7 \mu \mathrm{F}$,

Discharge Resistor, $\mathrm{R}_{2}=\frac{2}{2.3 \times 4.7 \times 10^{-6}}=185.01 \mathrm{k} \Omega$

Select $\mathrm{R}_{2}=180 \mathrm{k} \Omega$

For $\mathrm{C}_{\mathrm{a}}=22 \mu \mathrm{F}_{\mathrm{x}}$

Discharge Resistor, $\mathrm{R}_{3}=\frac{2}{2.3 \times 22 \times 10^{-6}}=39.53 \mathrm{k} \Omega$

Select $R_{a}=39 \mathrm{k} \Omega$

For $\mathrm{C}_{4}=47 \mu \mathrm{F}_{x}$

Discharge Resistor, $\mathrm{R}_{4}=\frac{2}{2.3 \times 47 \times 10^{-6}}=18.5 \mathrm{k} \Omega$

Select $R_{4}=18 \mathrm{k} \Omega$

Select delay time $=3 \mathrm{sec}$

\section{Software Development}

\section{A. Design Flow of the System}

Software implementation is an important part of this system.

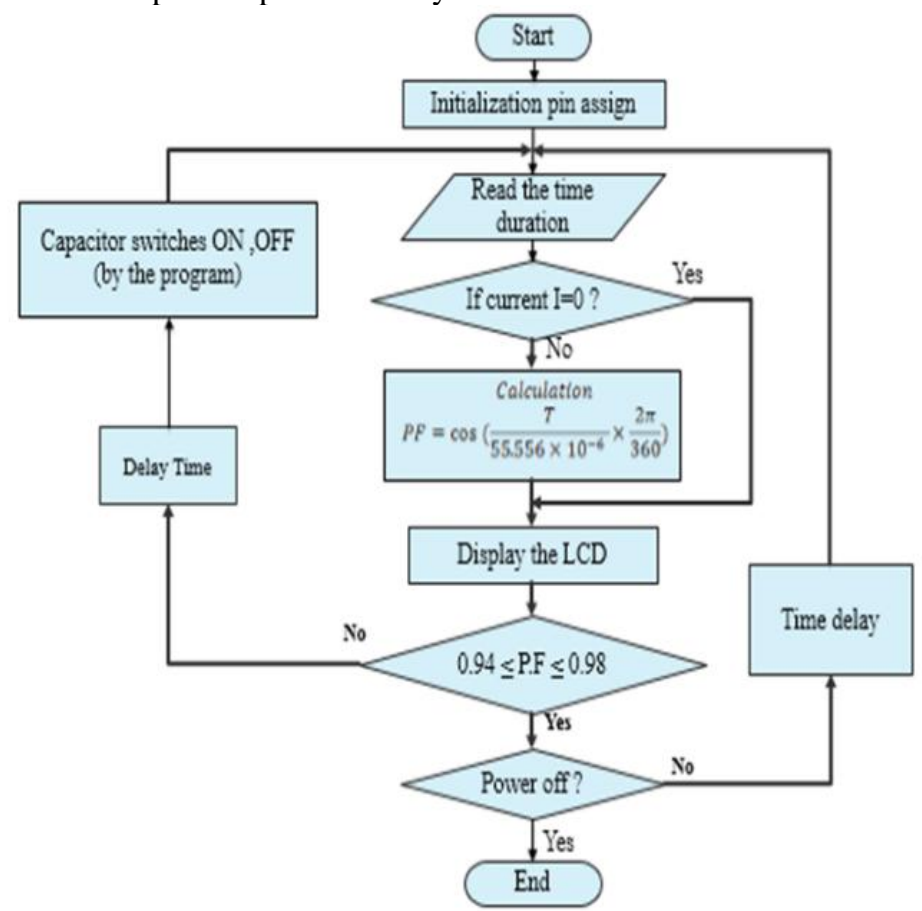

Figure. 4 Flow Chart of the Power Factor Measuring System

B. How to Find the Phase Angle by Using the Time Difference

For example,

$$
\begin{aligned}
& V=230 \angle 0^{\circ} \mathrm{V} \\
& I=20 \angle 60^{\circ} \mathrm{A} \text { ( Lagging) }
\end{aligned}
$$




$$
\begin{aligned}
& f=50 \mathrm{~Hz} \\
& T=\frac{1}{f}=\frac{1}{50}=20 \mathrm{~ms}
\end{aligned}
$$

For half cycle, $\frac{T}{2}=10 \mathrm{~ms}$

$$
\begin{aligned}
& 180^{\circ} \rightarrow 10 \mathrm{~ms} \\
& 1^{\circ} \rightarrow 10 \times \frac{1}{180}=0.055556 \mathrm{~ms}=55.556 \mu \mathrm{s}
\end{aligned}
$$

$55.556 \mu$ s time difference is the $1^{\circ}$ phase shift.

$60^{\circ}$ phase shift $\rightarrow T_{\text {difference }}=55.556 \mu \mathrm{s} \times 60$

$$
=3333.36 \mu \mathrm{s}
$$

\section{Power Factor Equation for Using Program}

$\mathrm{T}=$ Time duration between $\mathrm{V}$ and $\mathrm{I}$ waveform

$\theta=$ Phase shift

$$
\begin{aligned}
\text { P.F } & =\cos \theta \\
\theta & =\frac{T}{55.556 \mu}(\text { Deg: }) \\
\theta= & \frac{T}{55.556 \times 10^{-6}} \times \frac{2 \pi}{360}(\mathrm{Rad}:) \\
\text { P.F } & =\cos \theta \\
& =\cos \left(\frac{\mathrm{T}}{55.556 \times 10^{-6}} \times \frac{2 \pi}{360}\right)
\end{aligned}
$$

\section{Test And Results}

Software simulation and debugging of the firmware on PC using Proteus 7.7 professional software as shown in figures.

\section{A. Power Factor Measuring Without Compensated Capacitor} Motor $1 \mathrm{ON}$ condition

In Fig. 5, color yellow and red represent the voltage and current, and blue and green represent the voltage comparator output and current comparator output. Also LCD displays the power factor 0.64.

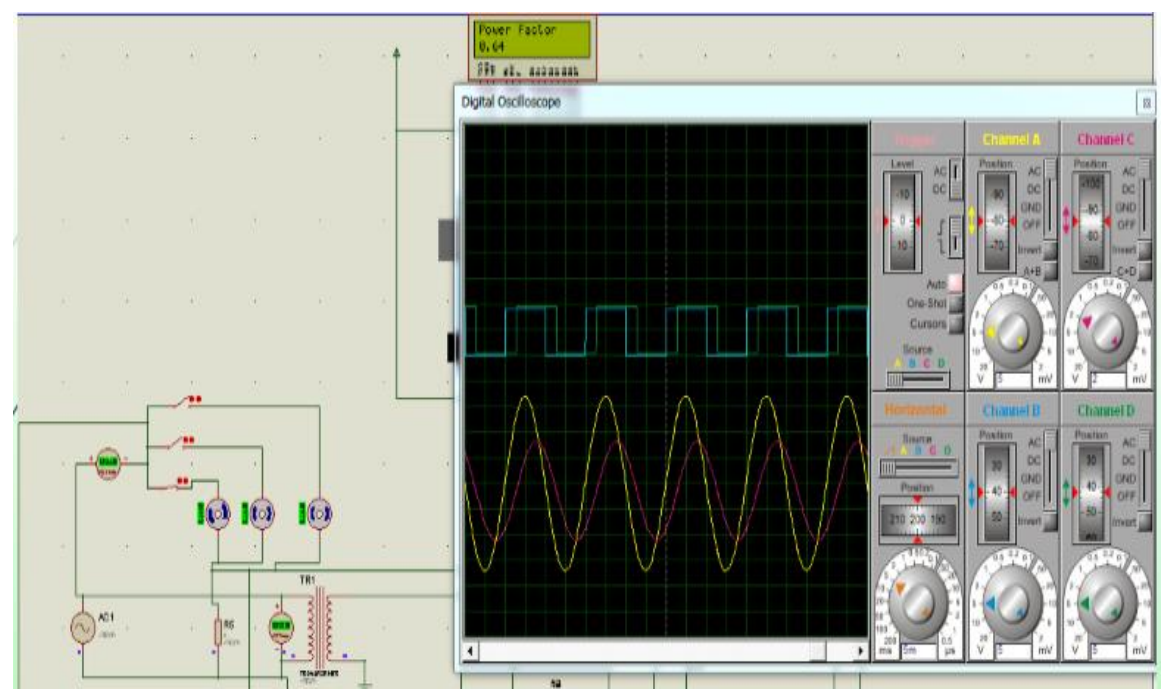

Figure. 5 Motor 1 ON Condition 
Motor 1 and 2 ON condition

In Fig. 6, the load 1 and load 2 are on condition and load 3 off. The simulated power factor 0.61 is seen on LCD and the wave forms colors are the same, mentioned above.

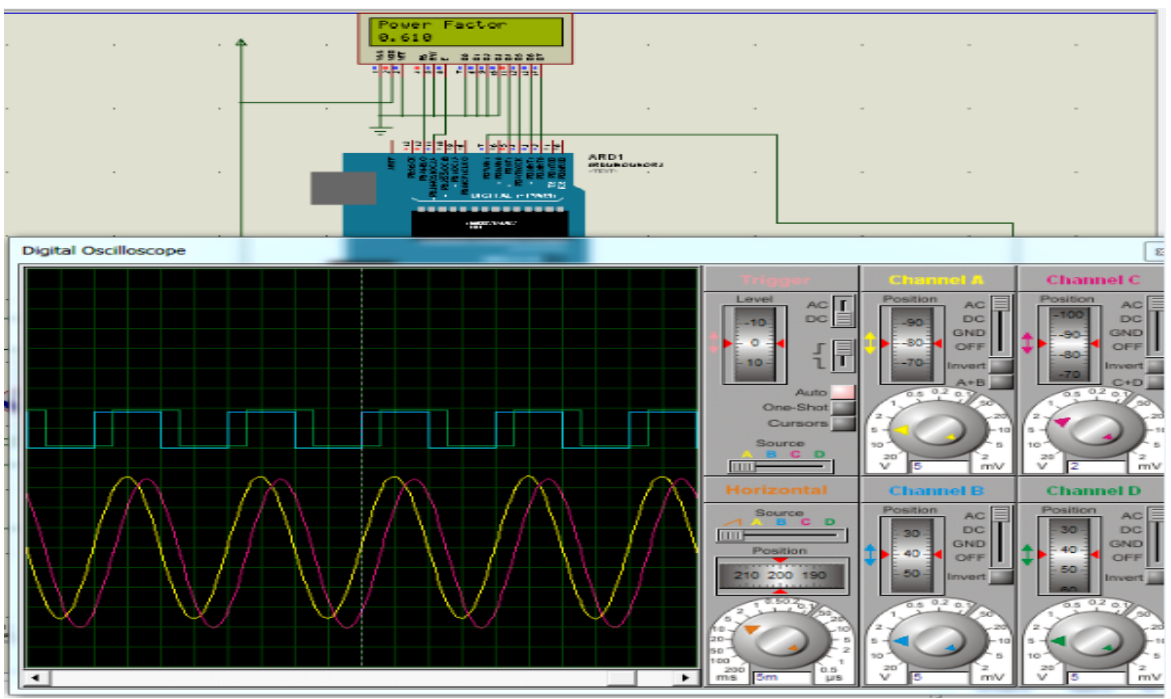

Figure. 6 Motor 1 and 2 ON Condition

Table 3 Comparison of Calculated Values and Simulated Values for Currents and Power Factor

\begin{tabular}{|c|c|c|c|c|c|}
\hline \multirow{2}{*}{ Motor ON Stage } & Calculated Values & \multicolumn{2}{l|}{ Simulated Values } & $\begin{array}{c}\text { \% error of } \\
\text { Power Factor }\end{array}$ \\
\cline { 2 - 5 } & Current (A) & $\begin{array}{l}\text { Power Factor } \\
\operatorname{Cos}(\Theta)\end{array}$ & Current $(\mathrm{A})$ & $\begin{array}{l}\text { Power Factor } \\
\operatorname{Cos}(\Theta)\end{array}$ & \\
\hline Motor 1 & 2.864 & 0.623 & 2.83 & 0.64 & $2.73 \%$ \\
\hline Motor 2 & 2.47 & 0.540 & 2.46 & 0.55 & $1.85 \%$ \\
\hline Motor 3 & 2.156 & 0.467 & 2.15 & 0.48 & $2.83 \%$ \\
\hline Motor 1+2 & 5.327 & 0.584 & 5.27 & 0.60 & $2.74 \%$ \\
\hline Motor 1+3 & 4.999 & 0.558 & 4.96 & 0.57 & $2.15 \%$ \\
\hline Motor 2+3 & 4.083 & 0.506 & 4.60 & 0.52 & $2.77 \%$ \\
\hline Motor 1+2+3 & 8.189 & 0.598 & 7.40 & 0.58 & $3.01 \%$ \\
\hline
\end{tabular}

\section{B. Power Factor Improvement Testing Using Solid State Switches with Capacitors}

In this section, the overall testing and results are described in detail with some figures.

No load Condition

In Fig. 7, because the total loads are off condition, LCD displays "No Load".

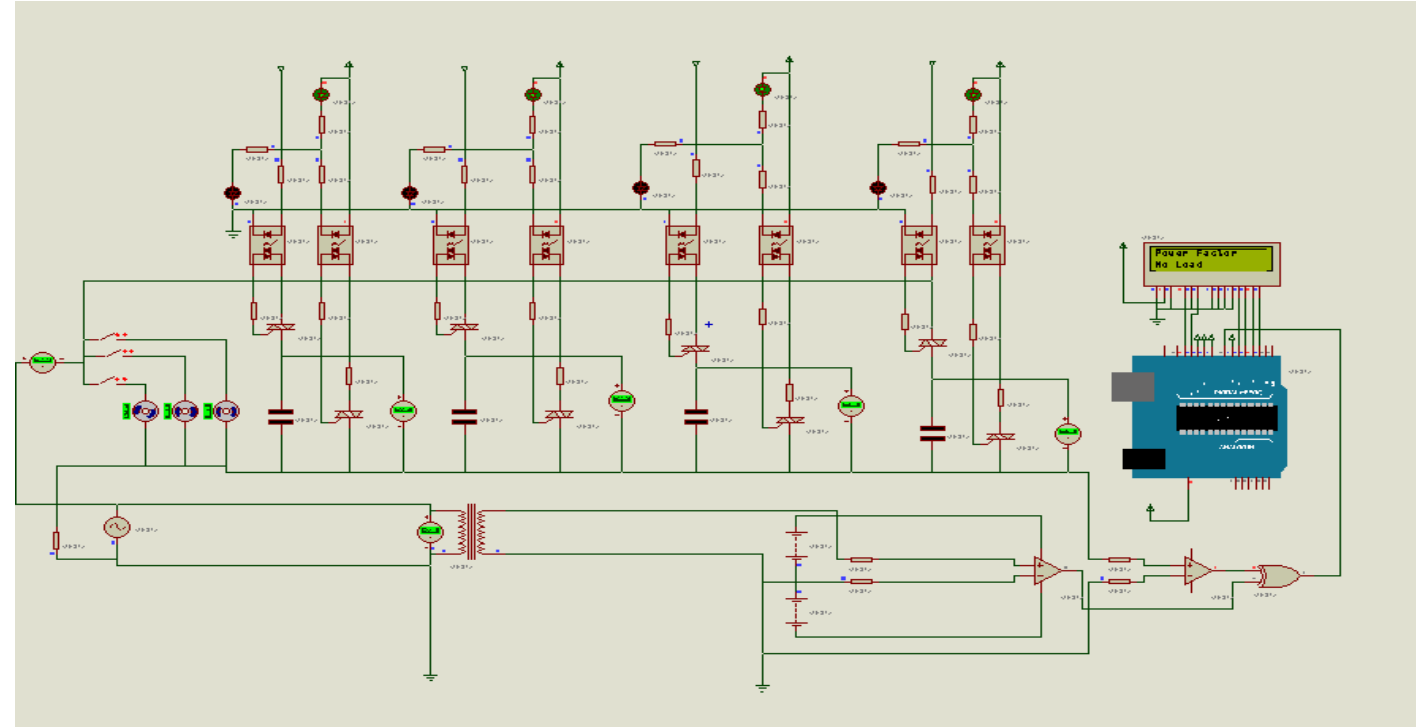

Fig. 7 NO Load Condition 
Motor 1 ON Condition

Fig. 8 mentions load 1 is on condition, the compensated capacitors 1 and 3 are activated and the power factor increased from 0.64 to 0.95 .

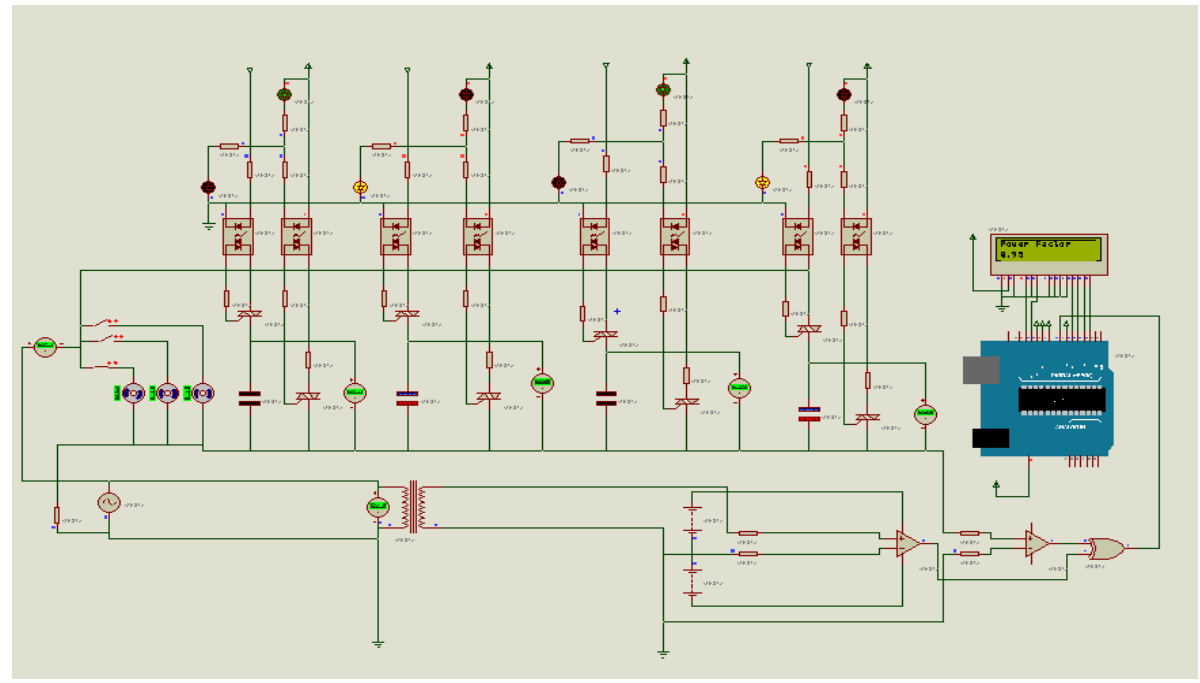

Fig. 8 Motor 1 ON with Compensated Capacitors

Simulated result

Switch 3 and $1 \mathrm{ON}$

$\mathrm{C}=22 \mu \mathrm{F}+2.2 \mu \mathrm{F}=24.2 \mu \mathrm{F}$

Power factor $=0.95$

Motor 1, 2 and 3 ON Condition

In Fig. 10, loads (Motor1, Motor 2 and Motor 3 ) are on condition, the compensated capacitors 3 and 4 are activated and the power factor increases from 0.58 to 0.94 .

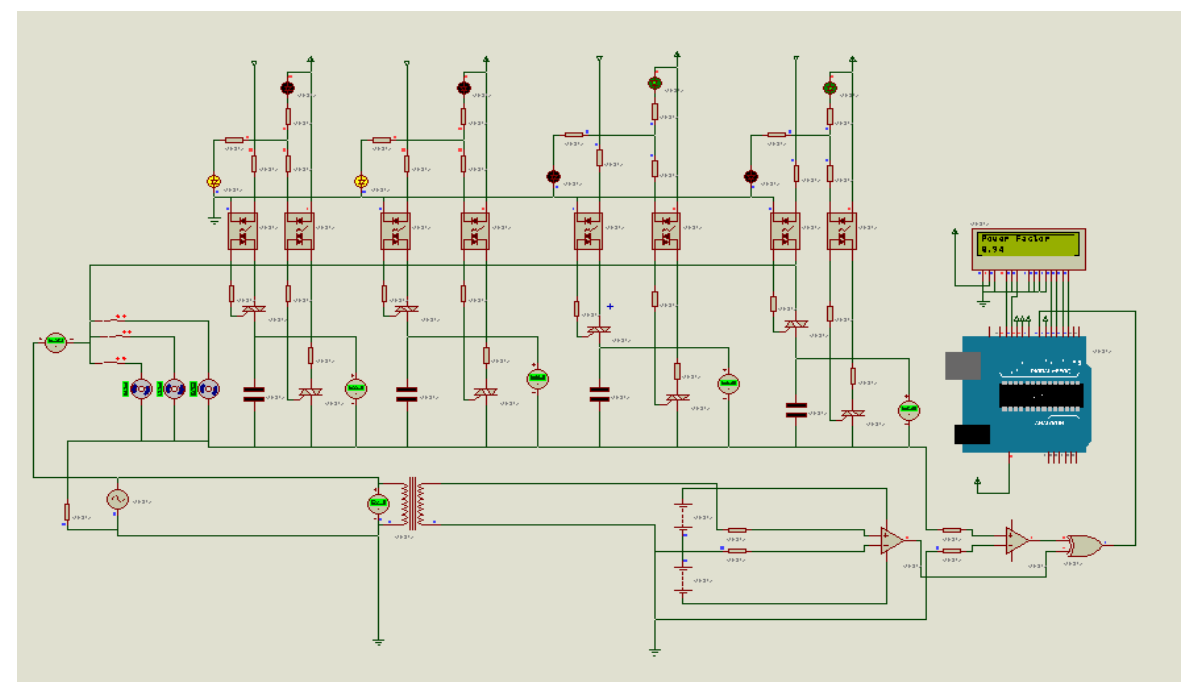

Fig. 10 Motor 1, 2 and 3 ON with Compensated Capacitors

Simulated result

Switch 4 and $3 \mathrm{ON}$

$\mathrm{C}=47 \mu \mathrm{F}+22 \mu \mathrm{F}=69 \mu \mathrm{F}$,

Power Factor $=0.94$

\section{Comparison of Calculated and Simulated Values of Compensated Capacitors}

The comparison of calculated and simulated values of compensated capacitors is shown in Table 4 . 
Table 4 Comparison of Calculated and Simulated Values of Compensated Capacitors

\begin{tabular}{|c|c|c|c|c|c|c|}
\hline $\begin{array}{l}\text { ON } \\
\text { Condition }\end{array}$ & $\begin{array}{l}\text { Initial } \\
\text { Power } \\
\text { Factor }\end{array}$ & $\begin{array}{l}\text { Target } \\
\text { Power } \\
\text { Factor }\end{array}$ & $\begin{array}{l}\text { Actual Final } \\
\text { Power Factor }\end{array}$ & $\begin{array}{l}\text { Capacitor } \\
\text { (calculated values) }\end{array}$ & $\begin{array}{l}\text { Capacitor } \\
\text { (simulated values) }\end{array}$ & $\%$ error \\
\hline NO load & 0 & 0 & 0 & 0 & 0 & 0 \\
\hline Motor 1 & 0.62 & 0.94 & 0.95 & 22.117 & 24.2 & 9.42 \\
\hline Motor 2 & 0.54 & 0.94 & 0.98 & 22.151 & 26.7 & 20.54 \\
\hline Motor 3 & 0.62 & 0.94 & 0.95 & 22.117 & 24.2 & 9.42 \\
\hline Motor 1,2 & 0.58 & 0.94 & 0.94 & 44.469 & 47 & 5.69 \\
\hline Motor 1,3 & 0.62 & 0.94 & 0.95 & 43.24 & 47 & 6.24 \\
\hline Motor 2,3 & 0.58 & 0.94 & 0.94 & 44.469 & 47 & 5.69 \\
\hline Motor $1,2,3$ & 0.60 & 0.94 & 0.94 & 66.039 & 69 & 4.48 \\
\hline
\end{tabular}

\section{Conclusions}

The PFC System with solid state switched capacitor is implemented completely. This system will provide for power factor improvement in low voltage system. Arduino UNO controller is very popular at this event, likewise easily to write the program by using the high level language. By the using of solid state switches, it can compare with the mechanical relays, so many reliable and efficient outcome appear. This is the very efficient system for various loads, by using the different sizes of capacitors and triggering the switches which were controlled by the program. Therefore, it is soundly recommended to come out the perfect benefits on the system which will be constructed as mentioned above.

\section{Acknowledgements}

The author would like to express her deepest gratitude to her family for their noble support, encouragement and unique loving kindness to attain her destination without any troubles. The author would be grateful to Dr. Tun Naing (Managing Director (Rtd) Myanmar Electric Power Interprise) for giving his suggestions and support during the preparation of this paper. The author sincerely wishes to thank all persons who helped her directly or indirectly towards the completion of this paper.

\section{References}

[1]. A.Bhatia, 2012, "Power Factor in Electrical Energy Management", 5272 Meadow Estates Drive, Fairfax, VA 22030-6658, Phone \& Fax: 703-988-0088, www.PDHonline.org, www.PDHcenter.com.

[2]. NOKIAN CAPACITORS, September, 2015, "Power Factor Correction",

[3]. Tel: +358 3388311 , Telefax: +358 33883 360, (http://www.nokiancapacitors.com).

[4]. Aashish, G., neharikaKapil and Sheila, M., 2014, "Implementation of Thyristor Switched Capacitors for Power Factor Improvement", ISSN 2231-1297, Volume 4, Number 3, 2014

[5]. (http:// www.ripuublication.com/aeee.htm)

[6]. Shamal padmawar", and Prof. Anil wamar. 2014, "Power Factor Correction based on PWM waves using PIC", ISSN: 2348 - 7968, IJISET, Volume.1, Issuse 6, August 2014.

[7]. PranjaliSonje, and AnaghaSoman, 2013, "Power Factor Correction Using PIC Microcontroller", ISSN: 2277 - 2008, ISO 9001:2008 Certified Journal, IJEIT, Volume.3, Issue4, October 2013. 